\title{
The New Construction Approach Adapted by Ashghal for the Public Projects in
} Qatar

\author{
Ahmad Al-Buenain \\ aa1304017@student.qu.edu.qa \\ College of Engineering, Qatar University, Doha, Qatar \\ Saeed Al-Muhanadi \\ sm1805291@student.qu.edu.qa \\ College of Engineering, Qatar University, Doha, Qatar \\ Mohammad Falamarzi \\ mf1407364@student.qu.edu.qa \\ College of Engineering, Qatar University, Doha, Qatar
}

\begin{abstract}
The purpose of this paper is to review the new strategy adapted by Ashghal to implement lean construction in Qatar to improve project performance and predictability of delivery. This is a significant change programme led by a government delivery entity. In 2017, the Public Works Authority (ASHGHAL) piloted the implementation of lean construction principles within 3 projects. Following realization of tangible benefits through the pilot application, Ashghal made it contractual to implement lean in all future projects. Since then, Ashghal has awarded 26 projects with the enhanced requirements in the construction contracts. The enhanced requirements within the construction contract are intended for improving public satisfaction and project delivery performance. This paper discusses the changes implemented by Ashghal and provides some recommendations. The paper presents findings from Literature reviews, interviews with Ashghal, and site visit to one of the projects undergoing the transformation. Qatar had not implemented lean construction principles at such large scale before 2018. Ashghal has realised various challenges in embedding the new strategy, which will be explored in this paper. Ashghal recognizes that the program requires time and effort, and has invested in building local capability. The enhanced requirements are applicable only to full infrastructure construction projects awarded post October 2018. Thereby the new approach is focused on contractors and supervision consultants' way of delivery. There is scope however to expand the application of lean principles to improve internal processes. Other influencing government agencies could also benefit from this program. Finally, this paper presents the efforts by Ashghal in raising the bar of delivery in the state of Qatar and the region. It is a rare example of a public sector authority leading a major change initiative that can benefit all parties involved and especially in construction, which makes this a very unique and special case that deserves to be written about.
\end{abstract}

Keywords: Enhancing delivery; Lean construction; Qatar; Public projects; Collaborative planning; Visual management

\section{INTRODUCTION}

Qatar, the country with one of the highest GDP per capita of 61,000 USD (PSA, 2017). Mainly driven by the large oil and gas reserves that makes it the largest exporter of Liquefied Natural Gas (LNG) in the world, in addition to the small population of approximately 2.7 million, has great ambition for the future. After successfully hosting 
2006 Asian games along with other international sporting events, Qatar decided to raise the bar by bidding to host 2022 FIFA World Cup. With large capital from its hydrocarbon sales, Qatar managed to develop a strong and extensive bid with huge developments to make the bid promising and attractive. In December 2010, FIFA announced that Qatar won the bid. This was a great motive to start developing the entire country to host such event. In addition, there was another major motive that made this development ambition double in magnitude, it was Qatar National Vision 2030, launched in 2008, with the aim to drive Qatar towards a knowledge-based economy rather than a Hydrocarbon based economy.

More than USD \$200bn was budgeted for the investment in the massive development of new roads, stadiums, facilities, and other major projects in the period between 20112022. Most of this budget is dedicated to the transport sector that is required to support FIFA 2022 World Cup and Qatar National Vision 2030 to meet the rapid infrastructure and economic growth (MME, 2016). The largest budget in the transport sector, 40 billion USD, is for Qatar National Rail Scheme, and the second largest budget in the transport sector, 14.6 billion USD, is for the Local Roads \& Drainage programme managed by the Public Works Authority, Ashghal. (Ashghal, 2018).

Ashghal is responsible for all infrastructure projects and public buildings in Qatar through their lifecycle from planning to asset management. A number of departments are established to handle this responsibility, these are design, roads, highway, drainage networks, and buildings departments. Large budgets are placed yearly to serve these departments to achieve their objectives, these went up to 18.8 billion Qatari Riyals in 2018 on roads projects and are 23 billion Qatari Riyals in 2019 for roads department (The Peninsula, 2019).

With this rapid and massive development in Qatar's infrastructure, Ashghal perceived that the current construction practices and the overall construction industry is underperforming and is facing issues. Some of these issues are the waste that is present in many forms, for example, over-production, waiting, inventories, defects, skills misuse and others. These issues cause projects to finish late and overbudget. Therefore, Ashghal realises a need for construction enhancement, and they are revising their strategy to improve construction productivity.

The purpose of this paper is to show efforts undertaken by Ashghal in implementing a program to enhance the delivery of construction projects in Qatar, and to analyse the program and the challenges associated with it. The paper aims to give observations and recommendations based on the review.

The paper starts with literature review on lean construction methods, benefits, and challenges. Then the research methodology and Ashghal program will be discussed. Finally, the paper will give conclusion and recommendations.

\section{BACKGROUND AND LITERATURE REVIEW}

Generally, construction is a project industry whose unique features are associated with one-of-a-kindness of the project, construction site, production set-up and temporary organization. Over the last couple of years, infrastructure construction has continued to grow and equally affected by factors which include but not limited to, economic conditions and government policies. In fact, construction performance of road project 
for example affects the productivity of several sectors of the economy. Evaluation of project failure by the Construction Managers Association of America reveals that usually about $50 \%$ of the work on the weekly plan are finished by the end of the stipulated week plan and that majority of these planning failures could be mitigated by construction contractors through active management of the variability (Ansah \& Sorooshian, 2017).

Down the history, construction has suffered from cost and time overruns. Among the most known example is the Sydney Opera House that costed about $\$ 102$ million in comparison to the estimated value of $\$ 7$ million and took a total of 10 years from an initial estimate of 4 years. (Gade, 2016). A good example that drew the attention of lean construction in the UK was the construction of Wembley Stadium. The cost was about two times the estimated cost and construction period as it surpassed the estimated construction time (Gade, 2016).

In addition, lack of reliability often delays smooth flow and results in efficiency losses as far as construction of road projects is concerned. Therefore, there is urgent need for a majority of contractors to adopt lean construction: unlike the traditional road building processes, lean construction minimizes waste of materials, time and ensures the safety of workers at the site; this produces maximum value for client and other relevant stakeholders.

\subsection{Lean construction methods}

Generally, there exist a number of lean construction methods and techniques: one of the methods of lean construction is lean work structuring (Tauriainen et al., 2016). Unlike the work breakdown structure, the lean work structuring integrates the processes with product design and extends the functions down to the systems, it evaluates when the various chunks of work will be done. Another method is schedules; in this case the phase milestones required to complete the project are often established. Unlike traditional construction management, detailed schedules generated at the beginning of the construction project do assure control of the entire project. Other method is the last planner system of controls.

\subsection{Benefits of lean construction}

In essence, lean construction has huge benefits; it is important to note that this approach enhances value generation as well as waste productions (Ferng \& Price, 2005). Value is usually produced by a methodology and processes, which are aimed at examining and equally clarifying the clients and stakeholders' needs/demands. Other advantages of lean construction include ensuring the delivery of product with a specified budget; minimization of direct costs associated with the construction projects by effective project delivery management and enhanced well-informed decision making at all the levels of the construction project. Furthermore, reduction of potential risk and maximization of reliability and accountability into construction project environment is possible. For instance, in the construction of the Turner Construction Co Tennesse Medical Center, incorporation of the Building Information Modeling (BIM) and lean construction; the cost of the project was reduced by approximately $\$ 3$ million and equally the project was delivered within the shortest time possible. Equally, the incorporation of lean construction management in the construction of Gerona building resulted in a 
decrease in the construction time and cost by $25 \%$ and $30 \%$ respectively.

\subsection{Challenges of lean construction}

Arguably, there exist quite a number of challenges or limitations associated with the implementation of lean construction strategies and methods. Ansah et al. (2016) found out that some of the barriers linked to the implementation of lean construction include: insufficient technical skills, incomplete designs, poor relationship between the contractors and clients and poorly defined individual duties and responsibilities during the project. Notably, training and educating workers on the various lean methods require a lot of time and commitment and therefore some employee may not be pleased with such changes. In essence, cohesive teamwork among the workers is vital for lean construction and thus if workers are not working in harmony, then chances are that the efficiency of the lean construction may be compromised and result into a breakdown of project schedules. Moreover, in order for the lean construction to work effectively and efficiently, all sections need to be in line with the construction management plan as breakdown in the chain results in failure of the lean methodology.

\subsection{Top countries implementing lean construction}

As examined by the lean construction Institute (Ansah et al., 2016), lean construction is popular and active in the following countries, namely: United States, United Kingdom, Denmark, Finland, Australia, Brazil, Chile, Peru, Singapore, Ecuador, Venezuela and Colombia. Although survey in the UK and the Netherlands shows that the construction has been slow in adopting the lean construction concepts (Angaya, 2012). Grana Montero, one of the biggest engineering and construction firms in Peru employed lean construction in about nine projects and realized an increase in profit from \$3million to $\$ 9.5$ milion. In Sweden, majority of small to medium-size construction firms have specialized in multi-story construction by employing extensive prefabrication strategies (Ogunbiyi et al., 2014). Among the established contractors, who majorly work with a traditional approach, which comprises of huge projects, organization as well as on-site work, a similar trend in specialization is seen. It is important to note that the specialization majorly is concerned with an increased usage of prefabricated construction items and client relationships. Ansah et al. (2016) noted that this specialization trend is attributed by factors such as reduced costs of construction.

\section{RESEARCH METHODOLOGY}

Methodology is the road to analyze and solve the research questions. In this section, the procedure of making the research and the step by step logic will be described. The purpose of the research is to demonstrate the process of transformation in Ashghal from the traditional construction to the application of lean construction. In order to achieve this study objectives, the researchers did intensive and extensive literature study through journals, conducted meetings with Ashghal management, and performed a site visit to one of the major projects that are implementing new lean strategy.

The literature study done for this project was aiming to gather information about general construction industry around the world, lean construction methods, benefits of lean construction, challenges of lean construction, and top countries in implementing 
lean construction. These topics were analyzed carefully in order to understand the situation around the world in implementing lean methods and to be prepared to conduct the research in Qatar.

The researchers focused in this project to meet with the concerned department in Ashghal and the meeting was conducted between the project team and Eng. Ahmad AlAnsari Technical Office Manager, Jenefer Alam lead for construction enhancements, and Don Ward manager of Construction Excellence international, where the research team adjusted the direction of the study to be a strategic and qualitative analysis due to limited data available when this study was conducted as the enhancements and lean initiative within Ashghal is at early stages of implementation. There is scope to expand this research in future to incorporate tangible benefits this initiative generates for Ashghal and the responses by the market in the state of Qatar.

Finally, the team did a site visit to one of the major projects that implemented the enhanced contracts. The main target of this step was to observe the site and listen to all of the stakeholders such as Ashghal representative, project consultant, and the contractor. In addition, close interacting with the new technique used in the project which was the performance center helped the researchers to know more about Ashghal new style in managing the project. Further details about this visit will be discussed below in this paper.

This paper will discuss all the collected information in the research discussion and the team will show their findings and recommendation to improve the new strategy of Ashghal. Then all the results will be concluded in the conclusion section. Knowing that the targeted audience for this study were chosen to be Ashghal as the whole study was about their strategy and projects as they may benefit from the recommendations. This project focused on lean construction and it's a good opportunity to show how lean construction are implemented at Qatar. In addition, road and infrastructure contractors in the region may know more about lean construction and how to help in improving the new projects while working with Ashghal and lastly, all who are interested to know more about lean construction in Qatar.

\section{DISCUSSION}

\subsection{The need for change}

In 2017, ASHGHAL embarked on a fact finding mission to identify the root causes for recurring issues in construction. A task force was established comprising personnel from contractors, supervision consultants, designers and Ashghal. With the help of construction experts brought in from UK and the extensive local knowledge, the task force completed several initiatives and presented their recommendations for improvement, after being in action for ten months. Their proposals were focused at improving public satisfaction and project delivery performance. Along with improvement proposals related to zonal delivery, public engagement, disruption minimization, early engagement; a proof of concept study was run for lean construction principles on three pilot projects.

\subsection{Initiative timeline}

The proof of concept for lean was established through some key tools such as collaborative planning, minimizing wasted effort, visual management and work study. 
For a period of five months the pilot projects were monitored and analyzed and in August 2017, the realized benefits from the pilot projects were concluded. This included improved productivity at no additional cost. Subsequently, the findings and recommendations of the task force were presented to the president of Ashghal and approval was obtained to embed the proposals as new requirements in the construction contract to raise the bar of project delivery. Alongside this, Ashghal incubated Construction Excellence, a nonprofit organization, to encourage further sharing of international best practice. In March 2018, Ashghal announced the launch of its enhanced contracts at the second industry briefing. And in October 2018, it awarded the first five contracts with the new authority's requirements (which included Lean), worth QAR 2.7 Billion (\$740 million) and of duration up to five years.

\subsection{Enhanced contracts}

The enhanced contract included authority's requirements such as 1- Zonal Deliver, which obligates the contractors to divide the projects into zones to reduce the disturbance to the residents and to help concentrate resources and efforts. 2-Improved public relations and stakeholder management, enabling better project planning by early engagement. 3Lean construction principles to reduce wasted efforts, improve collaborative delivery and increase productivity and predictability. 4- logistics, welfare and site housekeeping. 5- improved look and feel of the project site. An incentive was outlined for contractors to get a $40 \%$ of the saving through any value engineering proposals.

New KPIs were introduced in the enhanced contract. For 6 disciplines (health and safety and welfare, quality, project delivery, environment and sustainability, public relations and handover) the project would score positive points for leading and proactive indicators, and score negative points for incidents not acceptable by standard. The KPI scores are evaluated yearly and a $5 \%$ of the contract value tied to this. Thus, the contractor is motivated to perform on these disciplines and standards. Figure 1 below shows an example KPI score model.

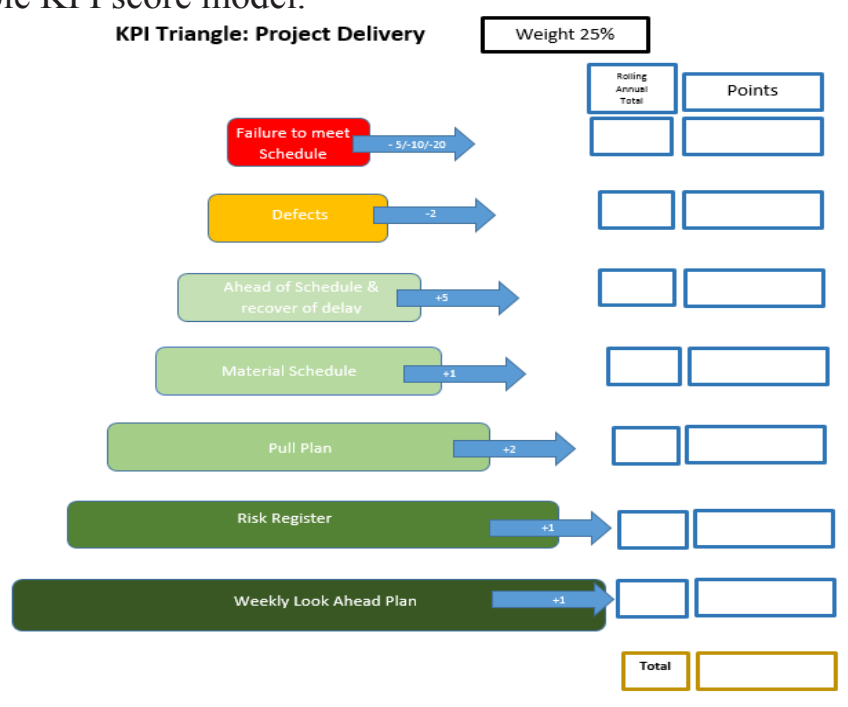

Figure 1: Monthly Performance Tracking Chart 


\subsection{Construction excellence}

Constructing excellence Qatar has been established by Ashghal in collaboration with Constructing Excellence from the United Kingdom. Constructing Excellence is a non-profit organisation which promotes industry best practice, energises collaboration through industry events and seminars, and provides tools for benchmarking project performance. In 2017 Ashghal embedded CE within its Technical office by part funding it. CE went on to expanding the awareness of Ashghal's construction improvement initiatives, including the implementation of the enhanced contracts and lean principles via several industry seminars, jointly hosted with professional institutions and academia. Thus CE helped facilitate the transformation program.

\subsection{Training program}

To ensure that their new lean construction strategy is understood and that all the stakeholders are aware of the changes and how they should be implemented, Construction Excellence Qatar have developed a training program for all their employees, contractors, Consultants. And other governmental stakeholders. The training program is divided into four different levels that are Intro, users, practitioners, and advanced practitioners. All ASHGHAL's and the stakeholders' staff members are obligated to take the training sessions with the level depending of his/her position and job nature. Figure 2 below shows the detailed structure of ASHGHAL's Lean Construction training program.

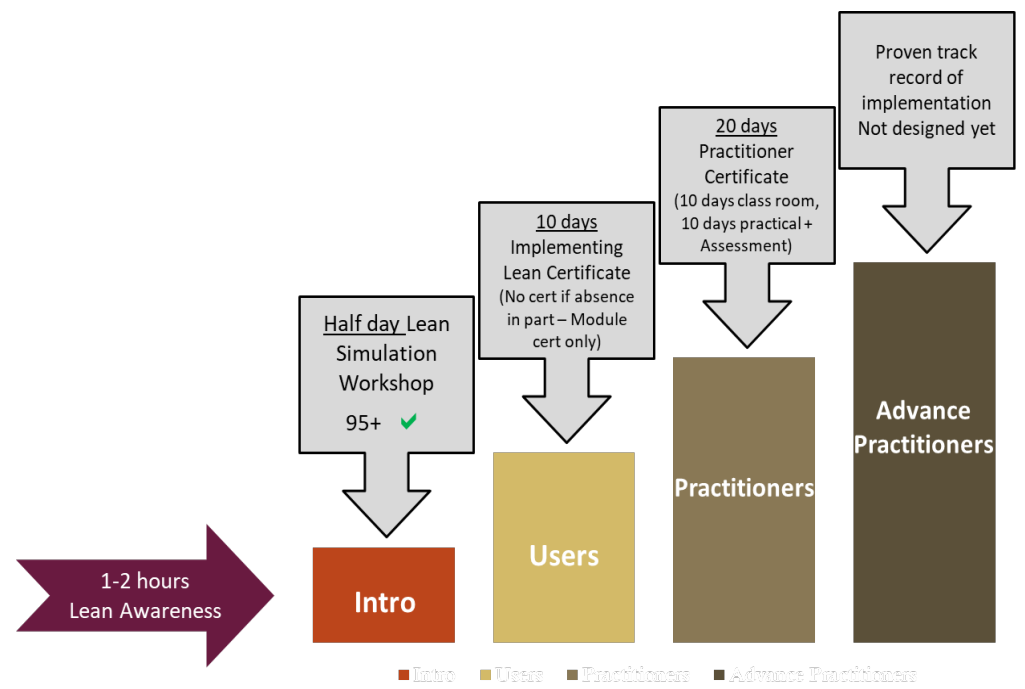

Figure 2: Lean Construction Training Program

\subsection{Lean implementation}

The new enhanced contracts include minimum requirements that aim in the implementation of lean strategies; these requirements are discussed in this section. The first requirement is to apply visual management by having a project performance center that displays appropriate information at worksite. This center is a place where all plans are displayed, and all equipment's and teams are shown on a map on each day to display where and what they are doing. Figures in the appendix show pictures of the project 
performance center that was visited. Another requirement is collaborative planning, this is by doing four weekly, including look ahead plans and pull production planning. The next requirement is the implementation of $5 \mathrm{~S}$ organization. Final requirement is to have structured problem solving to avoid defects and rework.

\section{CONCLUSION}

The construction industry is one of the slowest industries around the world to move towards technology or to implement any major changes. Therefore, seeing this kind of efforts being made by a governmental organization is a great sign that the construction industry in Qatar has finally found the needs for change and is going to change and improve soon. Also, this kind of governmental movement is what made Qatar ahead of all its neighbors in the regions since they only have some private companies that have implemented the usage of lean construction in their projects. Finally, the time is early now to say whether this program is successful or if it has improved the level of the projects in Qatar; however, this paper's intention was to show the efforts of the people in ASHGHAL and to increase the awareness in the construction industry that there is still a big room for improvement and change.

\section{RECOMMENDATIONS}

Although this paper's objectives were to show the efforts and to support this kind of initiatives in the construction industry. There are some improvements that we think are necessary to improve the outcome of this initiative and to enable its full potential. 1Applying the enhanced requirements on projects with different scopes like infrastructure, highway, and building projects would be more useful to measure and compare the effects of lean construction on each project type. 2- Applying internal changes in ASHGHAL regarding their approval durations and payment period to the contractors. In their initiative ASHGHAL assumes that all the delays are caused by the contractors and consultants however the studies have shown that many delays in construction projects are caused by the owners of the projects. 3- Increasing the collaboration between the different governmental agencies in order to increase the performance of the projects and success of the construction excellence initiative. 4- Using incentive in contracts to motivate the contractors in improving project delivery

\section{REFERENCES}

Alam, J, (2018), "Lean Construction, A Strategic Vision for Operational Excellence in Qatar", Warwick Univeristy, DLMBA programme

ANGAYA, A. (2012). Influence of Lean Construction on The Performance of Housing Scheme Building Projects in Nairobi County, 2-10.

Ansah, R. H. \& Sorooshian, S. (2017). Effect of lean tools to control external environment risks of construction projects. Sustainable cities and society, 32, 348-356.

Ansah, R. H., Sorooshian, S. \& Mustafa, S. B. (2016). Lean construction: an effective approach for project management. ARPN Journal of Engineering and Applied Sciences, 11(3), 16071612.

Ferng, J. \& Price, A. D. (2005). An exploration of the synergies between Six Sigma, total quality 
management, lean construction and sustainable construction. International Journal of Six Sigma and Competitive Advantage, 1(2), 167-187.

Gade, R. J. (2016). A proposed solution to the problem of construction industry overruns lean construction techniques and linear programming. Indian Journal of Science and Technology, $1-12$.

MME, (2016). Qatar National Development Framework. Retrieved from http://www.mme.gov. qa/QatarMasterPlan/Downloads-qnmp/QNDF/English/English_QNDF.pdf

Meeting with Eng. Ahmad AL-Ansari manager of the president technical office in the public works Authority (ASHGHAL).

Ogunbiyi, O., Goulding, J. S. \& Oladapo, A. (2014). An empirical study of the impact of lean construction techniques on sustainable construction in the UK. Construction innovation, 14(1), 88-107.

PSA (2017). Window on Economic Statistics of Qatar. Retrieved from https://www.psa. gov.qa/en/statistics/Statistical\%2 OReleases/Economic/GeneralEconomicStatistics/ windowonstatistics/2017/WinEconomicStat_23th_Issue_Q4_2017_AE.PDF.

Peninsula, (2019). https://thepeninsulaqatar.com/article/30/04/2019/Ashghal-budget-for-roadprojects-reaches -QR23-bi llion-in-2019

Tauriainen, M., Marttinen, P., Dave, B. \& Koskela, L. (2016). The effects of BIM and lean construction on design management practices. Procedia engineering, 164, 567-574. 